(c) American Dairy Science Association, 2005.

\title{
Effects of Canola Oil Dilution on Anhydrous Milk Fat Crystallization and Fractionation Behavior
}

\author{
A. J. Wright, H. D. Batte, and A. G. Marangoni \\ Department of Food Science, University of Guelph, Ontario, Canada, N1G 2W1
}

\section{ABSTRACT}

Blends of anhydrous milk fat (AMF) and canola oil (CO) were cooled from 35 to $5^{\circ} \mathrm{C}$ at $0.1^{\circ} \mathrm{C} / \mathrm{min}$, held for $24 \mathrm{~h}$, and centrifuged to separate the liquid and crystalline fractions. The blends' crystallization behaviors and microstructures depended on the level of $\mathrm{CO}$ present. Onset and half times of crystallization reflected a slower crystallization mechanism at higher levels of CO dilution. These differences were accompanied by a change in microstructure from large spherulites to smaller particles. The biggest change occurred between the 1:4 and 1:5 blends. Canola oil dilution also influenced the polymorphism of milk fat. Whereas only the $\beta^{\prime}$ polymorph was observed in the crystallized 1:2 blend, the $\beta$ polymorph predominated in the 1:8 blend. Some solubilization of AMF solids into $\mathrm{CO}$ was observed. This increased gradually with increasing CO concentration. Compositional analysis revealed the exchange of $\mathrm{AMF}$ and $\mathrm{CO}$ species between the liquid and crystalline fractions. The crystalline fractions were slightly enriched in AMF triacylglycerols, particularly with the more dilute blends (1:7 and 1:8). Large amounts of oil were trapped in the crystalline fractions, particularly for the concentrated AMF:CO blends where the $\beta^{\prime}$ crystals and spherulitic microstructures were observed. Although the solid fat content profiles of the fractionated blends were marginally higher than those of the starting blends, the samples were very soft and oily. This strategy of using CO to fractionate milk fat was limited by the poor separation of solids and liquid during centrifugation.

(Key words: canola oil, centrifugation, fractionation, milk fat)

Abbreviation key: AMF = anhydrous milk fat, $\mathbf{C O}=$ canola oil, $\mathbf{F A}$ = fatty acids, $\mathbf{S F C}=$ solid fat content, TAG $=$ triacylglycerols.

Received September 30, 2004.

Accepted March 3, 2005.

Corresponding author: A. J. Wright; e-mail: ajwright@uoguelph.ca.

\section{INTRODUCTION}

Milk fat contains hundreds of triacylglycerol (TAG) species, each with a unique melting temperature (Jensen and Newburg, 1995). The result is a plastic fat with a very wide melting range. Based on temperature, however, milk fat can be fractionated into chemically distinct groups of TAG. Several groups have documented the existence and properties of these fractions (McGillivray, 1972; Timms, 1980; Deffense, 1987; Makhlouf et al., 1987; Arul et al., 1988; Kaylegian and Lindsay, 1992; Rizvi and Bhaskar, 1995; Marangoni and Lencki, 1998; vanAken, et al., 1999; Wright et al., 2000b; Illingworth, 2002; Campos et al., 2003; Vanhoutte et al., 2003).

Milk fat is often discussed in terms of 3 fractions: the high-, middle-, and low-melting fractions. In reality, however, numerous fractions of unique composition can be obtained by fractional crystallization depending on the processing conditions, primarily crystallization temperature. Cooling rate, agitation, solvent properties, and the presence of additives also influence crystallization and the fractions obtained (Kaylegian and Lindsay, 1994; Illingworth, 2002).

Milk fat fractions have distinct chemical and physical properties and rheological characteristics. They have applications in various food products. For example, butter spreadability can be improved by fractionating milk fat and then recombining the fractions in various proportions (Kaylegian and Lindsay, 1992; Shukla et al., 1994; Illingworth, 2002). The fractions themselves have use in other foodstuffs. They function as high-melting shortenings in pastry making, as bloom inhibitors in chocolates, as butter-flavor-rich concentrates, and as texture modifiers in reduced-fat cheese curds (Kaylegian and Lindsay, 1992, 1994; Bhaskar et al., 1998; Kaylegian, 1999; Rosenberg, 2000).

Dry fractionation can be accomplished by crystallizing melted milk fat and separating the crystals from the liquid oil by various means. Solvent fractionation is a more efficient process, improving the separation of TAG during crystallization and allowing for washing of the crystals to minimize oil entrainment. Solvent fractionation has the disadvantages, however, that large quantities of solvent requiring disposal or recycl- 
ing are produced and that the nature of organic solvents requires extra safety precautions and lends an "unnatural" image to the products obtained.

A more friendly solvent-based approach would be attractive for milk fat fractionation. Previously, the effect of canola oil (CO) on the solubility and crystallization of milk fat fractions was studied (Wright et al., 2000b). Minimal interactions were observed between anhydrous milk fat (AMF) and CO TAG and ideal solubility was found for the higher-melting milk fat TAG in CO. As well, lower solubilities were observed for the highmelting fraction in $\mathrm{CO}$ than in low-melting fraction of AMF (Timms, 1978; Liang et al., 2003; Wright et al., 2003). These results indicate that CO might be a suitable solvent with which to fractionate milk fat in a safer and cleaner fashion. This paper explores the crystallization behavior of AMF-CO blends and the potential of fractionating AMF into value-added partially crystalline fractions using $\mathrm{CO}$ as a solvent.

\section{MATERIALS AND METHODS}

\section{Crystallization and Fractionation of AMF-CO Blends}

Anhydrous milk fat was combined with $\mathrm{CO}$ in 7 blends. Prepared on a weight basis, these were 1:2, 1:3, 1:4, 1:5, 1:6, 1:7, and 1:8 (AMF:CO). Anhydrous milk fat was melted at $60^{\circ} \mathrm{C}$ for $30 \mathrm{~min}$ before blending with CO. Three replicates of each blend were thoroughly mixed by vortexing and then heated to $60^{\circ} \mathrm{C}$ and held for $30 \mathrm{~min}$. The samples were placed in a water bath at $35^{\circ} \mathrm{C}$, held for $20 \mathrm{~min}$, and then cooled without agitation at $0.1^{\circ} \mathrm{C} / \mathrm{min}$ to $5^{\circ} \mathrm{C}$. Once at $5^{\circ} \mathrm{C}$, the slurries were held for $24 \mathrm{~h}$ before centrifugation at $5100 \times \mathrm{g}$ for 20 min using an IEC clinical centrifuge (Fisher Scientific, St. Louis, MO) placed in a walk-in cooler at $5^{\circ} \mathrm{C}$. The supernatant oil phase was then decanted leaving the partially crystalline pellet behind.

The crystallization of the AMF:CO blends was monitored by following the increases in solid fat content (SFC) using pulsed nuclear magnetic resonance. A Bruker mq20 Series NMR Analyzer (Bruker, Milton, Ontario, Canada) was used for this purpose. To characterize the crystallization kinetics, the resulting curves were fitted to the Avrami equation and half times of crystallization $\left(t_{1 / 2}\right)$ were determined as previously described (Wright et al., 2000a).

\section{SFC, Melting Behavior, Microstructure, and Polymorphism of the AMF:CO Blends}

The equilibrium SFC of the blends were determined according to the American Oil Chemists' Society Official Method Cd16-81 (AOCS, 1993). Melting temperatures of the blends were determined by differential scanning calorimetry using a Q-1000 DSC (TA Instruments Water-LLC, New Castle, DE). Between 8 and $10 \mathrm{mg}$ of each blend was sealed in an aluminum pan, heated to $60^{\circ} \mathrm{C}$ for $30 \mathrm{~min}$, and then crystallized at $5^{\circ} \mathrm{C}$. After 1 wk, the samples were melted from 5 to $60^{\circ} \mathrm{C}$ at a rate of $5^{\circ} \mathrm{C} / \mathrm{min}$, and end of melt temperatures determined. The crystal structures of the slurry blends after $24 \mathrm{~h}$ at $5^{\circ} \mathrm{C}$ were imaged using polarized light microscopy. A drop of each sample was placed on a glass microscope slide at $5^{\circ} \mathrm{C}$ and covered with a glass cover slip. The temperature of the slides was maintained at $5^{\circ} \mathrm{C}$ using a Linkham LTS350 cold stage (Linkham Scientific Instruments Inc., Surrey, UK). The samples were imaged using a $40 \times$ objective lens on an Olympus BH microscope (Olympus, Tokyo, Japan), a Sony XC75 CCD camera, and LG-3 capture board (Scion Corp., Frederick, MD).

For the x-ray diffraction analysis, 1.5 -mm glass capillary tubes were filled with the 1:2 and 1:8 AMF:CO blends. The samples were then melted at $60^{\circ} \mathrm{C}$ for 30 min, cooled to $35^{\circ} \mathrm{C}$ in a water bath, and held for 20 min before being statically cooled at $0.1^{\circ} \mathrm{C} / \mathrm{min}$ to $5^{\circ} \mathrm{C}$. The samples were held at $5^{\circ} \mathrm{C}$ for $24 \mathrm{~h}$ before analysis. Each sample was analyzed using a Huber Four Circle diffractometer (Huber Diffraktionstechnik, Rimsting, Germany) at $5^{\circ} \mathrm{C}$. An angular scan was performed between 15 and 25 two-theta at a resolution of $360 \mathrm{~s}$ per sampling interval with 240 intervals using a single point detector (Bicron, Canaan, CT). The lithium fluoride monochromator was set to select the $\mathrm{Cu}-\mathrm{K}$-alpha1 line of the sealed tube x-ray source (Enraf-Nonius, Delft, The Netherlands), lambda $=1.54 \AA$. The experiment was repeated for both an empty capillary and a capillary filled with $\mathrm{CO}$ at $5^{\circ} \mathrm{C}$. This background scattering was subtracted from each of the AMF:CO blends.

\section{Chemical and Physical Characterization of the Fractionated Oils and Pellets}

The fatty acid (FA) and TAG compositions of the fractionated oils and pellets were determined by GLC as previously described (Wright et al., 2000b). The equilibrium SFC of the pellet fractions was determined according to the American Oil Chemists' Society Official Method Cd16-81 (AOCS, 1993).

\section{Statistical Analyses}

Unless otherwise indicated, 3 replicates of each analysis were performed. The ANOVA was performed using GraphPad Prism, v4.0 (GraphPad Software Inc., San Diego, CA) to determine relationships between AMF:CO ratio and the onset time of crystallization $(\tau)$, temperature at crystallization onset $\left(\mathrm{T}_{\tau}\right)$, crystalliza- 
tion half times $\left(\mathrm{t}_{1 / 2}\right)$, maximum $\mathrm{SFC}\left(\mathrm{SFC}_{\max }\right)$, end of melt temperature $\left(\mathrm{T}_{\mathrm{m}}\right)$, and oil recovery for the blends. When a significant correlation was observed $(P<0.05)$, Tukey's multiple comparison testing was performed to identify differences between the individual treatments $(P<0.05)$.

\section{RESULTS AND DISCUSSION}

\section{Crystallization of the AMF:CO Blends}

Figure 1 shows the resulting crystallization curves for $\mathrm{AMF}$ and the $\mathrm{AMF}$ : $\mathrm{CO}$ blends during cooling from $35^{\circ} \mathrm{C}$ to $5^{\circ} \mathrm{C}$ at $0.1^{\circ} \mathrm{C} / \mathrm{min}$ and for $38 \mathrm{~h}$ after the samples reached $5^{\circ} \mathrm{C}$.

A significant delay in crystallization resulted when AMF was diluted with CO. Crystallization began around 100 min for AMF alone (Figure 1C) and after more than 200 min for the AMF-CO blends (Figure 1A). With an increasing proportion of $\mathrm{CO}$, a longer onset time to crystallization was observed $(P<0.01)$. Each sample began to crystallize before the target temperature of $5^{\circ} \mathrm{C}$ was reached (at $300 \mathrm{~min}$ ). In the earliest instance, solids were detected in the pure AMF around $106 \mathrm{~min}\left(\right.$ at $\left.24^{\circ} \mathrm{C}\right)$. In the latest instance, crystallization was observed in the 1:8 blend after 290 min (i.e., at $6^{\circ} \mathrm{C}$ ). The onset times and temperatures for the blends are shown in Table 1 along with the half times of crystallization, maximum SFC of the blends after $24 \mathrm{~h}$, the blends' end of melt temperatures, and the degree of undercooling for the blends at $5^{\circ} \mathrm{C}$.

According to Table 1, the blends with higher proportions of AMF began to crystallize at higher temperatures than the more dilute samples $(P<0.01)$. This is related to differences in undercooling between the blends. With increasing CO dilution, a decrease was observed in the end of melt temperature for the blends $(P<0.01)$. Consequently, at any given temperature, the more concentrated samples were more undercooled than the dilute blends and experienced a greater drive towards crystallization. This translates into differences in crystallization behavior and resulting network properties. It supports the observation that crystallization began earlier and proceeded more rapidly for the 1:2 blend versus the 1:8 blend, for example.

Each AMF:CO blend took approximately $24 \mathrm{~h}$ to reach a constant SFC value. Not surprisingly, the amount of solids formed depended on the amount of AMF in the blend. Figure 1 and Table 1 show that more solids were formed for the blends with higher levels of AMF. With AMF alone, $47 \%$ solids were present after $24 \mathrm{~h}$. At the same point, the 1:2 blend contained only $\sim 11.5 \%$ solids. This is not proportional to the decrease in solids expected based on the presence of CO (i.e., the 1:2 blend does not have an SFC of $15.7 \%$ or contain one-third of
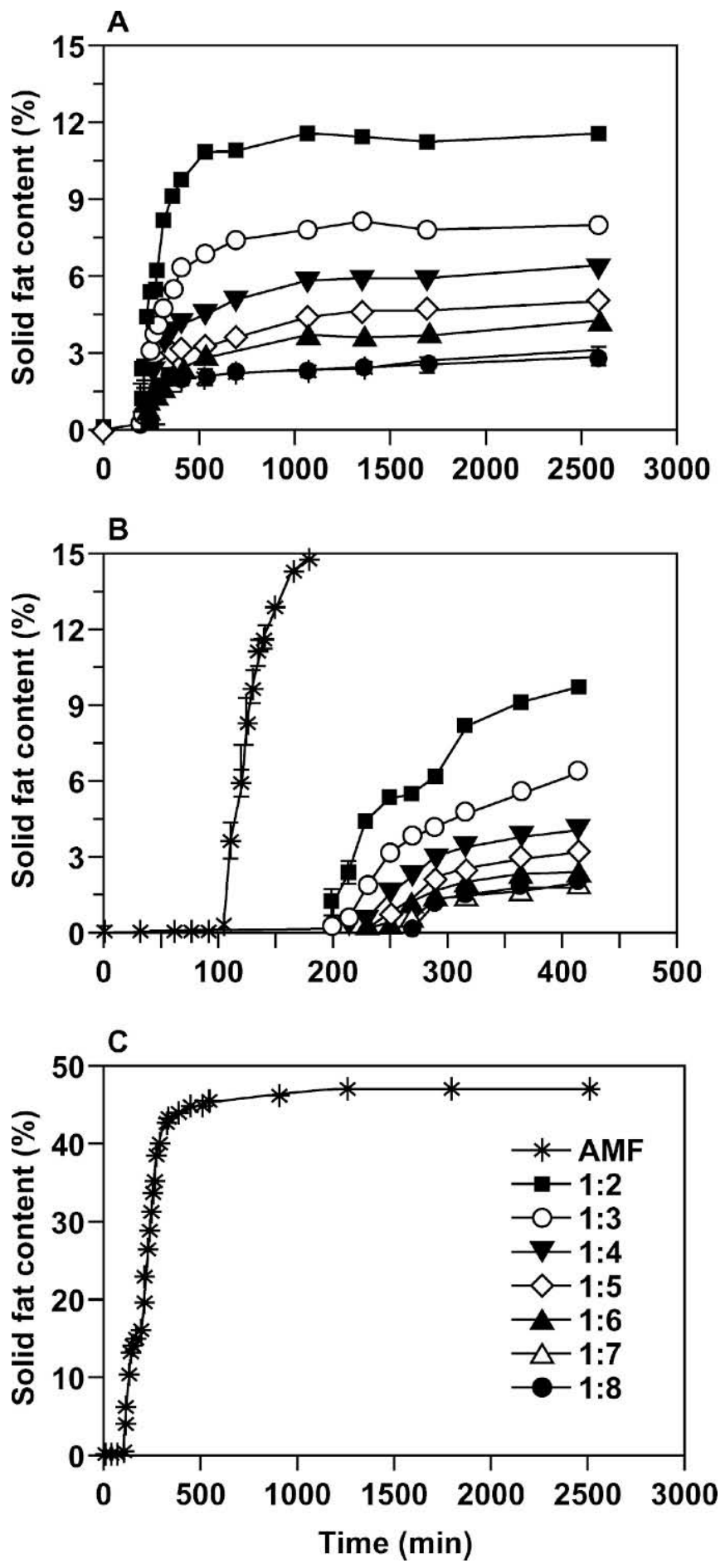

Figure 1. Solid fat content of anhydrous milk fat (AMF) and AMF:canola oil blends (1:2, 1:3, 1:4, 1:5, 1:6, 1:7, and 1:8, wt/wt) during cooling from 35 to $5^{\circ} \mathrm{C}$ at $0.1^{\circ} \mathrm{C} / \mathrm{min}$. Panels A and B show the crystallization during the first 3000 and $500 \mathrm{~min}$, respectively; $\mathrm{C}$ shows the crystallization behavior of AMF alone. 
Table 1. Onset times for crystallization ( $\tau$, min), temperatures at crystallization onset $\left(\mathrm{T}_{\tau},{ }^{\circ} \mathrm{C}\right)$, half times of crystallization $\left(\mathrm{t}_{1 / 2}, \mathrm{~min}\right)$, maximum $\mathrm{SFC}\left(\mathrm{SFC}_{\max }, \%\right)$, end of melt temperatures $\left(\mathrm{T}_{\mathrm{m}},{ }^{\circ} \mathrm{C}\right)$, and degree of undercooling at $5.0^{\circ} \mathrm{C}\left(\Delta \mathrm{T}_{5}{ }^{\circ} \mathrm{C},{ }^{\circ} \mathrm{C}\right)$ for anhydrous milk fat (AMF) and AMF:canola oil (CO) blends. ${ }^{1}$

\begin{tabular}{lllllll}
\hline $\begin{array}{l}\text { AMF:CO } \\
\text { blend }\end{array}$ & $\begin{array}{l}\tau \\
(\min )\end{array}$ & \multicolumn{1}{l}{$\begin{array}{l}\mathrm{T}_{\tau} \\
\left({ }^{\circ} \mathrm{C}\right)\end{array}$} & $\begin{array}{l}\mathrm{t}_{1 / 2} \\
(\mathrm{~min})\end{array}$ & $\begin{array}{l}\mathrm{SFC}_{\max } \\
(\%)\end{array}$ & \multicolumn{1}{l}{$\begin{array}{l}\mathrm{T}_{\mathrm{m}} \\
\left({ }^{\circ} \mathrm{C}\right)\end{array}$} & $\begin{array}{l}\Delta \mathrm{T}_{5}{ }^{\circ} \mathrm{C} \\
\left({ }^{\circ} \mathrm{C}\right)\end{array}$ \\
\hline $\mathrm{AMF}$ & $106 \pm 0.8^{\mathrm{a}}$ & $24.4 \pm 0.1^{\mathrm{a}}$ & $211.3 \pm 0.7^{\mathrm{a}}$ & $47.1 \pm 0.2^{\mathrm{a}}$ & $43.9 \pm 1.3^{\mathrm{a}}$ & 38.9 \\
$1: 2$ & $210 \pm 9.0^{\mathrm{b}}$ & $14.0 \pm 0.9^{\mathrm{b}}$ & $273.6 \pm 2.6^{\mathrm{b}}$ & $11.5 \pm 0.1^{\mathrm{b}}$ & $42.6 \pm 1.3^{\mathrm{ab}}$ & 37.6 \\
$1: 3$ & $228 \pm 3.0^{\mathrm{c}}$ & $12.0 \pm 0.0^{\mathrm{c}}$ & $295.0 \pm 3.6^{\mathrm{bc}}$ & $8.0 \pm 0.23^{\mathrm{c}}$ & $40.1 \pm 0.8^{\mathrm{abc}}$ & 35.1 \\
$1: 4$ & $249 \pm 1.2^{\mathrm{d}}$ & $10.0 \pm 0.0^{\mathrm{d}}$ & $317.0 \pm 4.4^{\mathrm{c}}$ & $6.4 \pm 0.22^{\mathrm{d}}$ & $39.9 \pm 0.6^{\mathrm{abc}}$ & 34.9 \\
$1: 5$ & $263 \pm 1.2^{\mathrm{de}}$ & $8.9 \pm 1.2^{\mathrm{de}}$ & $350.6 \pm 15.8^{\mathrm{d}}$ & $4.6 \pm 0.12^{\mathrm{e}}$ & $39.1 \pm 1.0^{\mathrm{bcd}}$ & 34.1 \\
$1: 6$ & $269 \pm 1.2^{\mathrm{ef}}$ & $8.0 \pm 1.2^{\mathrm{ef}}$ & $337.5 \pm 11.3^{\mathrm{d}}$ & $4.2 \pm 0.43^{\mathrm{f}}$ & $37.9 \pm 1.0^{\mathrm{cd}}$ & 32.9 \\
$1: 7$ & $283 \pm 12.0^{\mathrm{fg}}$ & $6.7 \pm 1.2^{\mathrm{fg}}$ & $340.2 \pm 5.5^{\mathrm{d}}$ & $3.1 \pm 0.42^{\mathrm{g}}$ & $36.3 \pm 0.7^{\mathrm{cd}}$ & 31.3 \\
$1: 8$ & $288 \pm 2.8^{\mathrm{gh}}$ & $6.0 \pm 0.0^{\mathrm{gh}}$ & $323.2 \pm 15.1^{\mathrm{d}}$ & $2.8 \pm 0.57^{\mathrm{g}}$ & $35.5 \pm 0.7^{\mathrm{d}}$ & 30.5 \\
\hline
\end{tabular}

a,b,c,d,e,f,g,h Within columns, blends with different superscripts differ $(P<0.05)$.

${ }^{1}$ Mean value of 3 replicates $\pm \mathrm{SE}$.

the AMF solids). Instead, $4.2 \%$ of the AMF solids are solubilized in $\mathrm{CO}$ during crystallization at $0.1^{\circ} \mathrm{C} / \mathrm{min}$ to $5^{\circ} \mathrm{C}$. Figure 2 shows the solubility behavior of $\mathrm{AMF}$ in $\mathrm{CO}$ for this study.

Anhydrous milk fat solubility depended on the concentration of $\mathrm{CO}$ in the blends. According to Figure 2A,
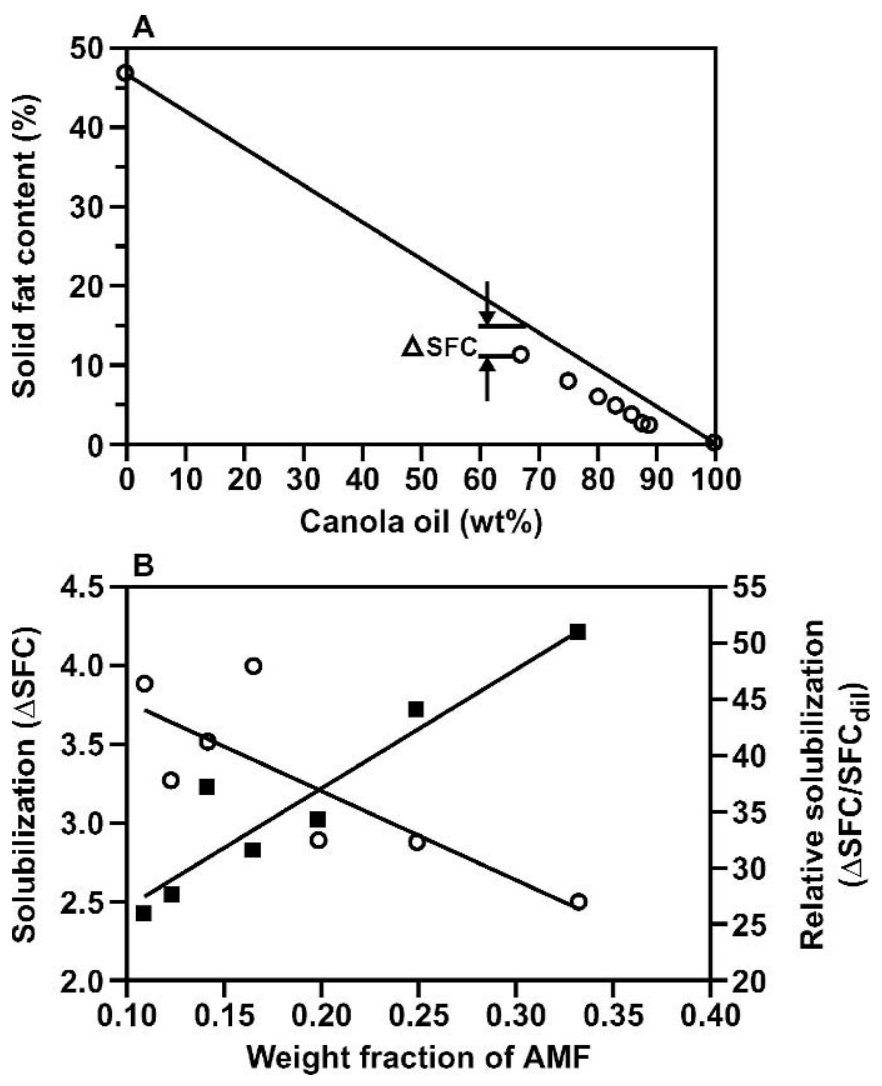

Figure 2. A) Solid fat content (SFC, \%) of anhydrous milk fat:canola oil (AMF:CO) blends after $24 \mathrm{~h}$ at $5^{\circ} \mathrm{C}$ as a function of $\mathrm{CO}$ (wt $\%$ ). Line indicates the $\mathrm{SFC}$ expected based on simple dilution $\left(\mathrm{SFC}_{\text {dil }}\right)$ of $\mathrm{AMF}$ with CO. B) Solubilization of AMF solids in $\mathrm{CO}(\triangle \mathrm{SFC}$ in Figure $2 \mathrm{~A}, \mathbf{\square})$, and relative solubilization $\left(\Delta \mathrm{SFC} / \mathrm{SFC}_{\mathrm{dil}}, \mathrm{O}\right)$ as a function of composition. fewer AMF solids were solubilized for the 1:2 versus the 1:8 blends, for example. The SFC of the more concentrated samples deviated further from the dilution line in Figure 2A than the more dilute blends ( $\triangle \mathrm{SFC}$ ). This extent of solubilization (i.e., the difference between the $\mathrm{SFC}$ expected based only on dilution $\left(\mathrm{SFC}_{\mathrm{dil}}\right)$ and the experimentally observed SFC in Figure 2A), is shown in Figure 2B. Although overall there were more solids solubilized with increasing AMF, relatively more solids were solubilized at higher concentrations of CO. In the more dilute blends, proportionally more solids were pulled into the liquid low-melting fraction and $\mathrm{CO}$; relative solubilization $\left(\triangle \mathrm{SFC} / \mathrm{SFC}_{\text {dil }}\right)$ ranged from 27 to $48 \%$ (Figure 2B). There was no abrupt change in the level of solubilization across the blends, but rather a progressive dissolution of AMF solids with $\mathrm{CO}$ dilution. With increased $\mathrm{CO}$ in the blends, relatively more solubilization and lower melting temperatures were observed $(P$ $<0.05$ ).

The sigmoidal nature of milk fat crystallization is evident from Figure 1, especially for the 1:2 blend where a secondary deposition of solids is observed around 300 min (Figure 1B). To characterize the crystallization behavior, the crystallization curves were fitted to the Avrami equation. Based on these fits, half times of crystallization $\left(t_{1 / 2}\right)$ were calculated. According to Table 1, $t_{1 / 2}$ tended to increase between the 1:2 and 1:4 blends. However, significant differences were not observed above this region between the 1:4 and 1:8 blends. This suggests similar crystallization mechanisms within the higher range of $\mathrm{CO}$ dilution. According to the Avrami equation, this could be related to different types of nucleation or dimensionality of growth, and to differences in growth rate. Such differences should be reflected in the microstructures of the resulting materials. Polarized light microscopy was used to explore the effects of AMF dilution and the different crystallization behaviors on blend microstructure after crystallization at $5{ }^{\circ} \mathrm{C}$ for $24 \mathrm{~h}$. These results are shown in Figure 3. 


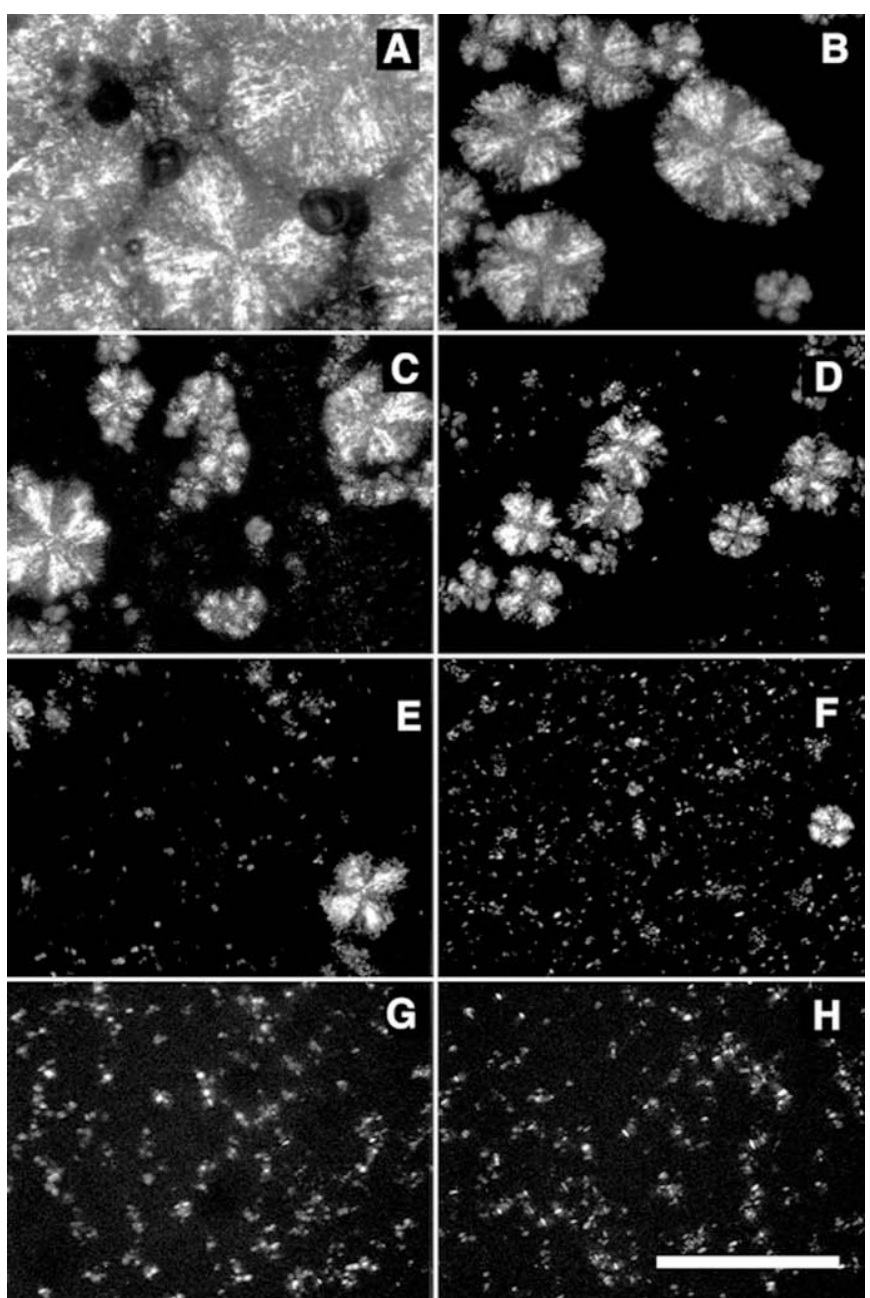

Figure 3. Polarized light micrographs of anhydrous milk fat (A) and anhydrous milk fat:canola oil blends [1:2 (B), 1:3 (C), 1:4 (D), 1:5 (E), 1:6 (F), 1:7 (G), and 1:8 (H)] cooled from 35 to $5^{\circ} \mathrm{C}$ at $0.1^{\circ} \mathrm{C} /$ min and held for $24 \mathrm{~h}$ at $5^{\circ} \mathrm{C}$. Magnification bar represents $100 \mu \mathrm{m}$.

Large differences were observed in the microstructures of the blends. Figure 3 shows that large spherulitic clusters with clear Maltese crosses were present in AMF and the 1:2, 1:3, and 1:4 blends. With increasing $\mathrm{CO}$ dilution, the clusters became smaller and more uniform in size. The 1:5 and 1:6 blends (Figure 3, panels $\mathrm{E}$ and F) contained very few spherulites. Only small, distinct microstructures were present in the 1:7 and 1:8 blends (panels $\mathrm{G}$ and $\mathrm{H}$ ). The changes in microstructure were most notable between the 1:4 (panel D) and 1:5 (panel E) blend, suggesting that AMF crystallizes differently in $\mathrm{CO}$ above and below this range of dilution. The differences in microstructure correlated with changes in blend crystallization behavior $\left(t_{1 / 2}\right.$ in Table 1). Anhydrous milk fat crystallized differently at low and high levels of $\mathrm{CO}$ dilution.

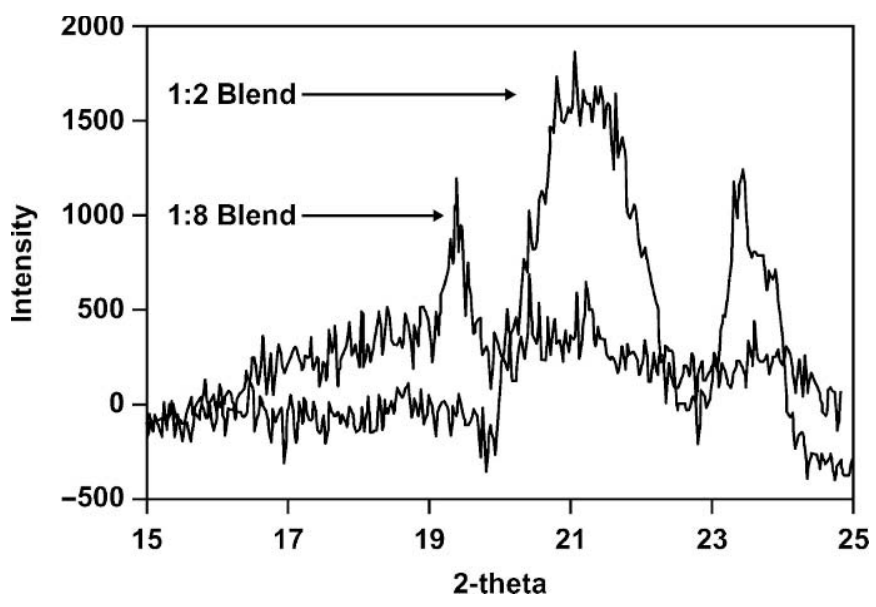

Figure 4. X-ray scattering intensity of 1:2 and 1:8 anhydrous milk fat:canola oil blends at $5^{\circ} \mathrm{C}$ corrected for glass capillary and canola oil scattering.

Based on blend melting temperature (see Table 1), an increased nucleation rate is expected for the more concentrated blends; the degree of undercooling is highest for the 1:2 blend. However, the resulting microstructures do not reflect this. Instead, the opposite would seem to be true. The large spherulites observed for AMF and the $1: 2$ and 1:3 blends indicate extensive crystal growth. Although the more concentrated AMF:CO samples had shorter induction times $(\tau)$, all the blends began to crystallize at roughly the same degree of undercooling (i.e., $\mathrm{T}_{\mathrm{m}}-\mathrm{T}_{\mathrm{c}}$ is between 28 and $30^{\circ} \mathrm{C}$ ). Anhydrous milk fat crystallization was observed at an undercooling of $20^{\circ} \mathrm{C}$. Microstructural differences may be related to the fact that, with increasing $\mathrm{CO}$ dilution, the potential level of solids is decreased. As a result, crystals that do form are more dispersed, and clustering and agglomeration are less likely.

The differences in microstructure may also reflect changes in AMF polymorphism with dilution. Figure 4 shows that differences were observed between the polymorphism of the 1:2 and 1:8 blends. After $24 \mathrm{~h}$ at $5^{\circ} \mathrm{C}$, only the $\beta^{\prime}$ polymorph was identified in the $1: 2$ blend [short spacings at $\sim 21.1$ and 23.4 two-theta (4.2 and $3.8 \AA$ ) ]. In contrast, the $\beta$ polymorph predominated in the 1:8 blend (short spacing at $~ 19.3$ two-theta or $4.6 \AA)$.

Although the $\beta$ polymorph has been reported in milk fat (deMan, 1961; Woodrow and deMan, 1968; Timms, $1979)$, the material is predominantly a $\beta^{\prime}$-fat. ten Grotenhuis et al. (1999), for example, did not identify the $\beta$ polymorph in milk fat. When Schaap et al. (1975) cooled milk fat to $28^{\circ} \mathrm{C}$ at $0.1^{\circ} \mathrm{C} / \mathrm{min}$, only the $\alpha$ and $\beta^{\prime}$ polymorphs were observed after $24 \mathrm{~h}$ of storage. The presence of liquid oil does influence polymorphic behav- 
Table 2. Recovery of starting canola oil (CO,\%) and pellet yield (\%) after centrifugation of anhydrous milk fat:canola oil (AMF:CO) blends at $5^{\circ} \mathrm{C} .{ }^{1}$

\begin{tabular}{lll}
\hline $\begin{array}{l}\text { AMF:CO } \\
\text { blend }\end{array}$ & $\begin{array}{l}\text { Recovery of } \\
\text { oil }(\%)\end{array}$ & $\begin{array}{l}\text { Yield of } \\
\text { pellet }(\%)\end{array}$ \\
\hline AMF & $\mathrm{NA}^{2}$ & $\mathrm{NA}$ \\
$1: 2$ & $35.6 \pm 4.6^{\mathrm{a}}$ & $229.0 \pm 6.5^{\mathrm{a}}$ \\
$1: 3$ & $69.9 \pm 1.0^{\mathrm{b}}$ & $190.4 \pm 2.1^{\mathrm{b}}$ \\
$1: 4$ & $78.6 \pm 1.3^{\mathrm{c}}$ & $185.7 \pm 3.6^{\mathrm{bc}}$ \\
$1: 5$ & $91.0 \pm 0.4^{\mathrm{d}}$ & $154.9 \pm 8.5^{\mathrm{cd}}$ \\
$1: 6$ & $94.5 \pm 0.6^{\mathrm{e}}$ & $132.9 \pm 2.5^{\mathrm{de}}$ \\
$1: 7$ & $99.3 \pm 0.6^{\mathrm{f}}$ & $111.0 \pm 10.8^{\mathrm{e}}$ \\
$1: 8$ & $99.7 \pm 0.0^{\mathrm{f}}$ & $102.5 \pm 0.0^{\mathrm{e}}$ \\
\hline
\end{tabular}

a,b,c,d,e,f,g Within columns, blends with different superscripts differ $(P<0.05)$.

${ }^{1}$ Mean value of 2 replicates $\pm \mathrm{SD}$.

${ }^{2} \mathrm{NA}=$ Not available as separation was not achieved during centrifugation.

ior. For example, Timms (1980) observed a $\beta^{\prime}$ to $\beta$ transformation in milk fat high-melting fraction during storage at $40^{\circ} \mathrm{C}$, but only in the presence of liquid oil. As in the current study, Rousseau et al. (1998) observed an increase in the $\beta$ polymorph with increasing dilution of lard in CO. The effects may be related to decreases in viscosity that alter TAG diffusion and allow more perfect crystals to form that subsequently adopt more stable polymorphic arrangements. $\beta$-Crystals have desirable functionalities in bakery shortenings. Their formation in this study and the potential applications warrants further exploration.

\section{AMF Fractionation with CO: Yield, Composition, and SFC}

After $24 \mathrm{~h}$, the partially crystalline blends were centrifuged at $5{ }^{\circ} \mathrm{C}$ to separate the liquid and partially crystalline fractions. The liquid oil was weighed and both fractions collected for further analysis. The solid fraction yield, recovery of the initial CO mass, and chemical composition of the supernatant oil and crystalline pellet fractions were determined. The recovery of oil was based on the amount of $\mathrm{CO}$ in the AMF:CO starting blends and calculated according to equation 1 .

$$
\text { Recovery of oil }(\%)=
$$

$$
100 \times \frac{\text { weight CO in blend }- \text { weight liquid fraction }}{\text { weight CO in blend }}
$$

Table 2 shows the recovery of liquid oil and yields of the partially crystalline fractions obtained by centrifugation. The high pellet yields (i.e., $>100 \%$ ) reflect the fact that large amounts of oil were trapped in the crystalline fractions.
When AMF was crystallized and centrifuged, no separation was observed. During the static crystallization, a feathery network of interconnected spherulitic clusters formed. The AMF crystallized as a solid mass of relatively high SFC. The centrifugation was insufficient to disrupt the network and the oil remained trapped within. With increasing levels of $\mathrm{CO}$, however, better separations between the liquid and pellet fractions were achieved. According to Table 2, less oil was entrained in the pellet with higher levels of $\mathrm{CO}$ in the blends. For the 1:2 blend, nearly $64 \%$ of the weight of the original CO remained trapped within the partially crystalline fraction. Only $36 \%$ of the starting CO mass was recovered. Correspondingly, the partially crystalline pellet for this sample constituted nearly $230 \%$ of the starting AMF weight. Rather than fractionating the milk fat into a higher melting crystalline fraction, a blended product was produced. The separation of AMF solids was poor, particularly with lower proportions of $\mathrm{CO}$ present. For the 1:7 and 1:8 blends, nearly all of the initial CO mass was recovered, although the pellets still contained large amounts of liquid oil. Differences in the compositions of the liquid and solid fractions are discussed later.

Table 2 shows that, although the ratio of AMF:CO influenced the separation, significant amounts of oil (either $\mathrm{CO}$ or low-melting fraction) remained in the pellet fractions in all cases. Although co-crystallization of $\mathrm{CO}$ within the AMF solids is not expected (Wright et al., 2000b), oil entrapment is a common problem in fractions obtained by melt crystallization (Breeding and Marshall, 1995).

When milk fat was previously fractionated using ethyl acetate as a solvent, a yield of $12 \%$ solids was observed at $5^{\circ} \mathrm{C}$ (Marangoni and Lencki, 1998). In this study, AMF achieved an SFC of roughly $47 \%$ at $5^{\circ} \mathrm{C}$ (Figure 1C). Therefore, if a perfect separation of liquid and solid fractions occurred, a yield of $\sim 16 \%$ solids would be expected for the 1:2 blend. This was not the case. Although the CO did solubilize some milk fat solids, the failure of centrifugation to separate the liquid and solid TAG limited the success of this approach. The physical entrapment of oil was highest in the 1:2 blend (Table 2). With higher solids, there is more surface area for the oil to adhere to in the most concentrated blends. Furthermore, microstructural differences between the crystallized blends may explain the differences in oil entrainment (see Figure 3, panels B vs. H). Slow cooling under quiescent conditions results in large spherulitic clusters, which can be difficult to separate from liquid oil (Black, 1975). With increasing CO dilution (Figure 3 ), a shift from the loose spherulites to more individually separated particles occurs. This formation of more 
Table 3. Triacylglycerol composition (carbon number, wt\%) of anhydrous milk fat (AMF), canola oil (CO), and initial AMF:CO blends. ${ }^{1}$

\begin{tabular}{|c|c|c|c|c|c|c|c|c|c|}
\hline \multirow{2}{*}{$\begin{array}{l}\text { Carbon } \\
\text { no. }\end{array}$} & \multirow[b]{2}{*}{$\mathrm{AMF}$} & \multirow[b]{2}{*}{$\mathrm{CO}$} & \multicolumn{7}{|c|}{ AMF:CO blend } \\
\hline & & & $1: 2$ & $1: 3$ & $1: 4$ & $1: 5$ & $1: 6$ & $1: 7$ & $1: 8$ \\
\hline 26 & $0.6 \pm 0.04$ & $\mathrm{ND}^{2}$ & 0.2 & 0.1 & 0.1 & 0.1 & 0.1 & 0.1 & 0.1 \\
\hline 28 & $0.6 \pm 0.03$ & $0.1 \pm 0.01$ & 0.3 & 0.2 & 0.2 & 0.2 & 0.2 & 0.2 & 0.2 \\
\hline 30 & $1.0 \pm 0.1$ & ND & 0.4 & 0.3 & 0.2 & 0.2 & 0.2 & 0.1 & 0.1 \\
\hline 32 & $2.2 \pm 0.1$ & ND & 0.7 & 0.5 & 0.4 & 0.4 & 0.3 & 0.3 & 0.2 \\
\hline 34 & $5.3 \pm 0.2$ & ND & 1.8 & 1.3 & 1.1 & 0.9 & 0.8 & 0.7 & 0.6 \\
\hline 36 & $10.5 \pm 0.2$ & ND & 3.5 & 2.6 & 2.1 & 1.8 & 1.5 & 1.3 & 1.2 \\
\hline 38 & $12.7 \pm 0.2$ & $0.9 \pm 0.02$ & 4.9 & 3.9 & 3.3 & 2.9 & 2.6 & 2.4 & 2.3 \\
\hline 40 & $10.2 \pm 0.2$ & ND & 3.4 & 2.6 & 2.1 & 1.7 & 1.5 & 1.3 & 1.1 \\
\hline 42 & $6.9 \pm 0.2$ & ND & 2.3 & 1.7 & 1.4 & 1.2 & 1.0 & 0.9 & 0.8 \\
\hline 44 & $6.5 \pm 0.2$ & ND & 2.2 & 1.6 & 1.3 & 1.1 & 0.9 & 0.8 & 0.7 \\
\hline 46 & $7.7 \pm 0.2$ & $0.4 \pm 0.2$ & 2.8 & 2.2 & 1.8 & 1.6 & 1.4 & 1.3 & 1.2 \\
\hline 48 & $9.8 \pm 0.2$ & $0.5 \pm 0.4$ & 3.6 & 2.9 & 2.4 & 2.1 & 1.9 & 1.7 & 1.6 \\
\hline 50 & $12.4 \pm 0.1$ & $1.4 \pm 0.8$ & 5.1 & 4.2 & 3.6 & 3.2 & 3.0 & 2.8 & 2.6 \\
\hline 52 & $10.2 \pm 0.1$ & $13.8 \pm 0.3$ & 12.6 & 12.9 & 13.1 & 13.2 & 13.3 & 13.3 & 13.4 \\
\hline 54 & $3.4 \pm 0.2$ & $77.7 \pm 2.0$ & 52.9 & 59.1 & 62.8 & 65.3 & 67.1 & 68.4 & 69.4 \\
\hline 56 & $0.6 \pm 0.04$ & $5.2 \pm 0.01$ & 3.7 & 4.1 & 4.3 & 4.4 & 4.6 & 4.6 & 4.7 \\
\hline
\end{tabular}

uniformly sized, rod-shaped crystals that will form compact aggregates during filtration is one benefit of solvent fractionation. To further quantify the level of oil entrainment in the pellets and to explore the partitioning of liquid AMF and CO TAG between the fractions, compositional analysis was performed. Tables 3 and 4 show the initial TAG and FA composition of AMF, $\mathrm{CO}$, and the AMF:CO blends.

Tables 3 and 4 show that there are TAG and FA species unique to AMF or CO. Accordingly, C36, 12:0, and 14:0 will be used as markers for AMF, whereas C54 will be used as a marker for CO. In Table 3, the most dilute blends (1:7 and 1:8) had lower concentrations of the short- and medium-chain TAG that are present in milk fat (C30 to C50), and higher concentrations of the longer chain TAG associated with CO (C52 to C56). Similarly, Table 4 shows the decrease in the AMF-prevalent FA (4:0 to 18:0) and the increase in CO-prevalent FA (18:1 to 22:0) with dilution. During crystallization and centrifugation, the AMF and $\mathrm{CO}$ molecules partitioned between the liquid and partially crystalline fractions. The TAG and FA compositions of the liquid fractions are shown in Tables 5 and 6, respectively.

Table 4. Fatty acid composition (wt\%) of anhydrous milk fat (AMF), canola oil (CO), and initial AMF:CO blends. $^{1}$

\begin{tabular}{|c|c|c|c|c|c|c|c|c|c|}
\hline \multirow{2}{*}{$\begin{array}{l}\text { Fatty } \\
\text { acid }\end{array}$} & \multirow[b]{2}{*}{$\mathrm{AMF}$} & \multirow[b]{2}{*}{$\mathrm{CO}$} & \multicolumn{7}{|c|}{ AMF:CO blend } \\
\hline & & & $1: 2$ & $1: 3$ & $1: 4$ & $1: 5$ & $1: 6$ & $1: 7$ & $1: 8$ \\
\hline $4: 0$ & $2.8 \pm 0.1$ & $\mathrm{ND}^{2}$ & 0.9 & 0.7 & 0.6 & 0.5 & 0.4 & 0.4 & 0.3 \\
\hline $6: 0$ & $2.0 \pm 0.1$ & ND & 0.7 & 0.5 & 0.4 & 0.3 & 0.2 & 0.3 & 0.2 \\
\hline $8: 0$ & $1.0 \pm 0.03$ & ND & 0.3 & 0.3 & 0.2 & 0.2 & 0.2 & 0.1 & 0.1 \\
\hline $10: 0$ & $2.6 \pm 0.1$ & ND & 0.9 & 0.7 & 0.5 & 0.4 & 0.4 & 0.3 & 0.3 \\
\hline $12: 0$ & $3.2 \pm 0.1$ & ND & 1.1 & 0.8 & 0.6 & 0.5 & 0.5 & 0.4 & 0.4 \\
\hline $14: 0$ & $10.5 \pm 0.2$ & ND & 3.5 & 2.6 & 2.1 & 1.8 & 1.5 & 1.3 & 1.2 \\
\hline $14: 1$ & $1.6 \pm 0.03$ & ND & 0.5 & 0.4 & 0.3 & 0.3 & 0.2 & 0.2 & 0.2 \\
\hline $15: 0$ & $1.2 \pm 0.03$ & ND & 0.4 & 0.3 & 0.2 & 0.2 & 0.2 & 0.1 & 0.1 \\
\hline $16: 0$ & $30.0 \pm 0.2$ & $4.4 \pm 0.4$ & 12.9 & 10.8 & 9.5 & 8.7 & 8.1 & 7.6 & 7.3 \\
\hline $16: 1$ & $3.0 \pm 0.02$ & $0.5 \pm 0.1$ & 1.3 & 1.1 & 1.0 & 0.9 & 0.8 & 0.8 & 0.7 \\
\hline $17: 0$ & $0.8 \pm 0.04$ & ND & 0.3 & 0.2 & 0.2 & 0.1 & 0.1 & 0.1 & 0.1 \\
\hline $18: 0$ & $10.2 \pm 0.1$ & $2.6 \pm 0.2$ & 5.2 & 4.5 & 4.2 & 3.9 & 3.7 & 3.6 & 3.5 \\
\hline $18: 1$ & $25.8 \pm 0.3$ & $72.1 \pm 0.5$ & 56.7 & 60.6 & 62.9 & 64.0 & 65.5 & 66.4 & 67.0 \\
\hline $18: 2$ & $3.7 \pm 0.4$ & $13.5 \pm 0.02$ & 10.2 & 11.0 & 11.5 & 11.9 & 12.1 & 12.3 & 12.4 \\
\hline $18: 3$ & $1.6 \pm 0.2$ & $6.4 \pm 0.1$ & 4.8 & 5.2 & 5.4 & 5.6 & 5.7 & 5.8 & 5.9 \\
\hline $22: 0$ & ND & $0.5 \pm 0.01$ & 0.3 & 0.3 & 0.4 & 0.4 & 0.4 & 0.4 & 0.4 \\
\hline
\end{tabular}

${ }^{1}$ Mean value of 2 replicates $\pm \mathrm{SD}$; values for blends were calculated based on AMF and CO composition. ${ }^{2} \mathrm{ND}=$ Species not detected 
Table 5. Triacylglycerol composition (carbon number, wt\%) of anhydrous milk fat (AMF), canola oil (CO), and the liquid fractions for each AMF:CO blend. ${ }^{1}$

\begin{tabular}{|c|c|c|c|c|c|c|c|c|c|}
\hline \multirow{2}{*}{$\begin{array}{l}\text { Carbon } \\
\text { no. }\end{array}$} & \multirow[b]{2}{*}{$\mathrm{AMF}$} & \multirow[b]{2}{*}{$\mathrm{CO}$} & \multicolumn{7}{|c|}{ AMF:CO blend } \\
\hline & & & $1: 2$ & $1: 3$ & $1: 4$ & $1: 5$ & $1: 6$ & $1: 7$ & $1: 8$ \\
\hline 26 & $0.6 \pm 0.04$ & $\mathrm{ND}^{2}$ & $0.3 \pm 0.01$ & $0.2 \pm 0.01$ & $0.2 \pm 0.01$ & $0.1 \pm 0.01$ & $0.1 \pm 0.01$ & $0.1 \pm 0.04$ & $0.1 \pm 0.01$ \\
\hline 30 & $1.0 \pm 0.1$ & ND & $0.4 \pm 0.02$ & $0.3 \pm 0.01$ & $0.2 \pm 0.01$ & $0.2 \pm 0.01$ & $0.2 \pm 0.02$ & $0.1 \pm 0.01$ & $0.1 \pm 0.01$ \\
\hline 32 & $2.2 \pm 0.1$ & ND & $0.8 \pm 0.04$ & $0.6 \pm 0.02$ & $0.4 \pm 0.01$ & $0.3 \pm 0.01$ & $0.3 \pm 0.04$ & $0.2 \pm 0.01$ & $0.2 \pm 0.01$ \\
\hline 34 & $5.3 \pm 0.2$ & ND & $1.5 \pm 0.2$ & $1.1 \pm 0.1$ & $0.8 \pm 0.02$ & $0.6 \pm 0.01$ & $0.5 \pm 0.04$ & $0.4 \pm 0.01$ & $0.4 \pm 0.01$ \\
\hline 36 & $10.5 \pm 0.2$ & ND & $2.6 \pm 0.4$ & $1.9 \pm 0.1$ & $1.5 \pm 0.04$ & $1.2 \pm 0.02$ & $1.0 \pm 0.02$ & $0.9 \pm 0.02$ & $0.9 \pm 0.1$ \\
\hline 42 & $6.9 \pm 0.2$ & ND & $1.3 \pm 0.1$ & $0.9 \pm 0.02$ & $0.7 \pm 0.01$ & $0.5 \pm 0.01$ & $0.4 \pm 0.02$ & $0.4 \pm 0.02$ & $0.4 \pm 0.01$ \\
\hline 44 & $6.5 \pm 0.2$ & ND & $1.0 \pm 0.02$ & $0.7 \pm 0.03$ & $0.6 \pm 0.01$ & $0.4 \pm 0.03$ & $0.3 \pm 0.04$ & $0.3 \pm 0.02$ & $0.4 \pm 0.0$ \\
\hline 46 & $7.7 \pm 0.2$ & $0.4 \pm 0.2$ & $1.2 \pm 0.3$ & $0.8 \pm 0.2$ & $0.9 \pm 0.01$ & $0.8 \pm 0.02$ & $0.7 \pm 0.1$ & $0.6 \pm 0.01$ & $0.7 \pm 0.1$ \\
\hline 48 & $9.8 \pm 0.2$ & $0.5 \pm 0.4$ & $1.5 \pm 0.8$ & $1.1 \pm 0.6$ & $1.6 \pm 0.1$ & $1.4 \pm 0.1$ & $1.4 \pm 0.3$ & $1.0 \pm 0.1$ & $1.1 \pm 0.1$ \\
\hline 50 & $12.4 \pm 0.1$ & $1.4 \pm 0.8$ & $2.4 \pm 0.7$ & $2.3 \pm 0.6$ & $2.6 \pm 0.2$ & $2.5 \pm 0.01$ & $2.2 \pm 0.2$ & $1.9 \pm 0.1$ & $1.9 \pm 0.01$ \\
\hline 52 & $10.2 \pm 0.1$ & $13.8 \pm 0.3$ & $12.2 \pm 0.5$ & $12.3 \pm 0.1$ & $12.5 \pm 0.2$ & $12.5 \pm 0.2$ & $12.0 \pm 0.4$ & $11.7 \pm 0.04$ & $12.1 \pm 0.1$ \\
\hline 54 & $3.4 \pm 0.2$ & $77.7 \pm 2.0$ & $64.6 \pm 0.9$ & $69.0 \pm 1.3$ & $70.1 \pm 0.6$ & $72.3 \pm 0.1$ & $73.8 \pm 0.3$ & $75.0 \pm 0.4$ & $74.7 \pm 0.2$ \\
\hline
\end{tabular}

${ }^{1}$ Mean value of 2 replicates $\pm \mathrm{SD}$.

${ }^{2} \mathrm{ND}=$ Species not detected

The liquid fractions contained TAG and FA from both CO (C54) and AMF (C36, 12:0, and 14:0). Therefore, the liquid fractions were blends of AMF and $\mathrm{CO}$ species. With increasing $\mathrm{CO}$ dilution, the composition of these fractions was more similar to CO. The increase in C54 in the fractions (Table 5) was proportional to the increase in C54 in the starting blends (Table 3). The ratio of C54 in the liquid fraction to C54 in the starting blend was constant, but greater than unity $(\sim 1.1$ to 1.2$)$ for all blends. Therefore, the liquid fractions were slightly enriched in CO TAG over the starting blends, but not above that expected based on initial composition of the blends. Similarly, in Table 5, a decrease in C36 (an
AMF TAG) is observed for the liquid fractions with increasing $\mathrm{CO}$ dilution. This decrease is again proportional to the decrease in C36 observed when AMF was diluted with $\mathrm{CO}$ (see Table 3); the ratio of C36 in the liquid fraction to C36 in the starting blend is $~ 0.75$ for all the blends. Therefore, the liquid fractions were depleted in AMF TAG relative to the starting blends, although the ratio of AMF:CO did not detectably affect the partitioning of AMF into the liquid fraction. The liquid fractions were a mixture of AMF and CO TAG.

Similarly, some AMF FA were present in the liquid fractions. The decrease in 12:0 and 14:0 with higher CO dilution was again proportional to blend composition

Table 6. Fatty acid composition (wt\%) of anhydrous milk fat (AMF), canola oil (CO), and the liquid fractions for each AMF:CO blend. ${ }^{1}$

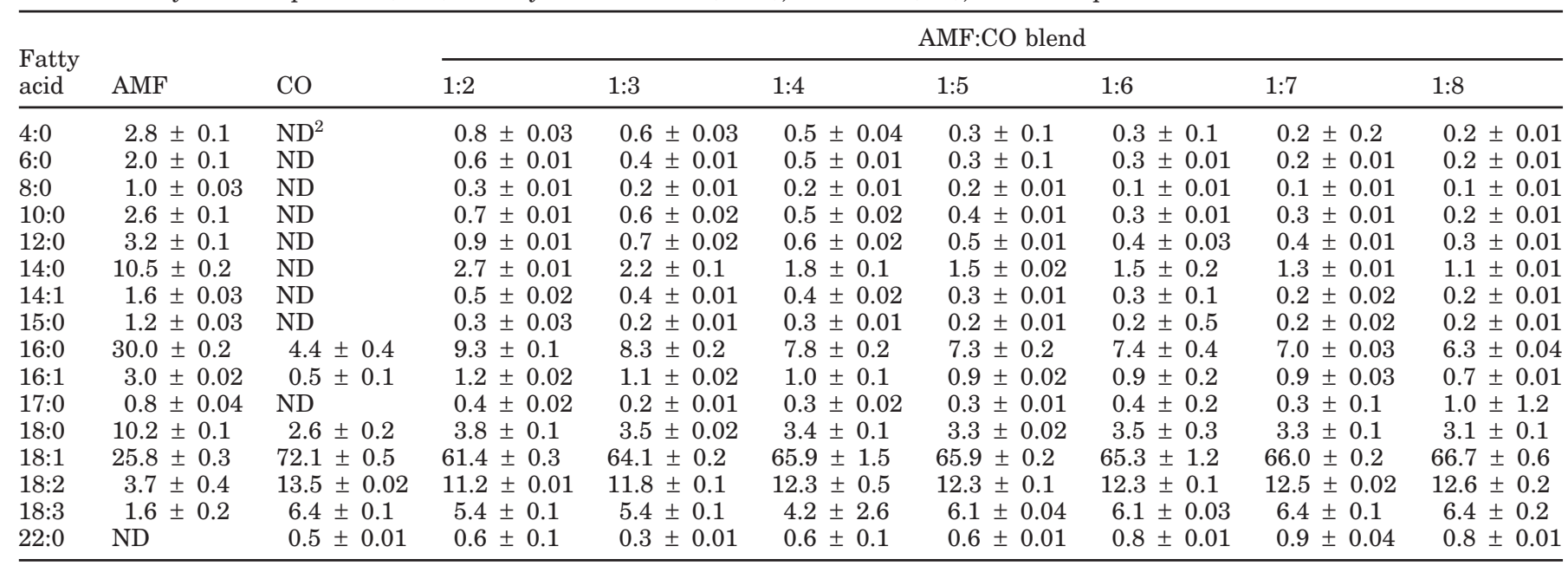

${ }^{1}$ Mean value of 2 replicates $\pm \mathrm{SD}$.

${ }^{2} \mathrm{ND}=$ Species not detected . 
Table 7. Fatty acid composition (wt\%) of anhydrous milk fat (AMF), canola oil (CO), and the crystalline fractions for each AMF:CO blend. ${ }^{1}$

\begin{tabular}{|c|c|c|c|c|c|c|c|c|c|}
\hline $\begin{array}{l}\text { Fatty } \\
\text { acid }\end{array}$ & $\mathrm{AMF}$ & $\mathrm{CO}$ & \multicolumn{7}{|c|}{ AMF:CO blend } \\
\hline $4: 0$ & $2.8 \pm 0.1$ & $\mathrm{ND}^{2}$ & $0.7 \pm 0.3$ & $0.6 \pm 0.03$ & $0.4 \pm 0.1$ & $0.4 \pm 0.1$ & $0.2 \pm 0.04$ & $0.3 \pm 0.03$ & $0.2 \pm 0.01$ \\
\hline $8: 0$ & $1.0 \pm 0.03$ & ND & $0.3 \pm 0.1$ & $0.3 \pm 0.01$ & $0.2 \pm 0.02$ & $0.2 \pm 0.02$ & $0.2 \pm 0.01$ & $0.1 \pm 0.01$ & $0.1 \pm 0.01$ \\
\hline $10: 0$ & $2.6 \pm 0.1$ & ND & $0.7 \pm 0.3$ & $0.7 \pm 0.01$ & $0.6 \pm 0.04$ & $0.5 \pm 0.1$ & $0.5 \pm 0.01$ & $0.4 \pm 0.01$ & $0.4 \pm 0.01$ \\
\hline $12: 0$ & $3.2 \pm 0.1$ & ND & $0.9 \pm 0.4$ & $0.9 \pm 0.01$ & $0.8 \pm 0.03$ & $0.7 \pm 0.1$ & $0.7 \pm 0.02$ & $0.7 \pm 0.1$ & $0.6 \pm 0.02$ \\
\hline $14: 0$ & $10.5 \pm 0.2$ & ND & $4.0 \pm 0.1$ & $3.3 \pm 0.02$ & $3.5 \pm 0.4$ & $2.9 \pm 0.1$ & $2.6 \pm 0.01$ & $2.5 \pm 0.04$ & $2.8 \pm 0.1$ \\
\hline $16: 0$ & $30.0 \pm 0.2$ & $4.4 \pm 0.4$ & $14.2 \pm 0.4$ & $13.0 \pm 0.1$ & $12.6 \pm 0.5$ & $12.5 \pm 0.2$ & $11.4 \pm 0.03$ & $11.4 \pm 0.3$ & $11.9 \pm 0.3$ \\
\hline $16: 1$ & $3.0 \pm 0.02$ & $0.5 \pm 0.1$ & $1.3 \pm 0.02$ & $1.1 \pm 0.01$ & $1.1 \pm 0.1$ & $1.0 \pm 0.04$ & $0.9 \pm 0.01$ & $0.9 \pm 0.04$ & $0.8 \pm 0.01$ \\
\hline $17: 0$ & $0.8 \pm 0.04$ & ND & $0.5 \pm 0.04$ & $0.4 \pm 0.01$ & $0.6 \pm 0.3$ & $0.4 \pm 0.04$ & $0.4 \pm 0.01$ & $0.4 \pm 0.01$ & $0.4 \pm 0.01$ \\
\hline $18: 0$ & $10.2 \pm 0.1$ & $2.6 \pm 0.2$ & $5.7 \pm 0.1$ & $5.4 \pm 0.02$ & $5.9 \pm 0.2$ & $5.9 \pm 0.04$ & $5.4 \pm 0.03$ & $5.5 \pm 0.02$ & $6.2 \pm 0.1$ \\
\hline $18: 1$ & $25.8 \pm 0.3$ & $72.1 \pm 0.5$ & $56.4 \pm 0.5$ & $57.4 \pm 0.1$ & $57.2 \pm 1.2$ & $58.3 \pm 1.2$ & $59.5 \pm 0.02$ & $59.5 \pm 0.6$ & $58.5 \pm 0.5$ \\
\hline $18: 2$ & $3.7 \pm 0.4$ & $13.5 \pm 0.02$ & $10.2 \pm 0.4$ & $10.3 \pm 0.01$ & $10.7 \pm 0.1$ & $10.9 \pm 0.1$ & $11.1 \pm 0.01$ & $11.2 \pm 0.01$ & $11.1 \pm 0.2$ \\
\hline $18: 3$ & $1.6 \pm 0.2$ & $6.4 \pm 0.1$ & $3.3 \pm 1.9$ & $5.0 \pm 0.1$ & $4.6 \pm 1.1$ & $4.8 \pm 1.3$ & $5.6 \pm 0.02$ & $5.7 \pm 0.02$ & $5.7 \pm 0.04$ \\
\hline
\end{tabular}

${ }^{1}$ Mean value of 2 replicates \pm SD.

${ }^{2} \mathrm{ND}=$ Species not detected.

(compare Tables 4 and 6). For example, the ratio of 12:0 in the liquid fraction to 12:0 in the initial blend was between 0.8 and 1.0 across the blends. Therefore, based on TAG and FA composition, the liquid fractions were slightly enriched in $\mathrm{CO}$ and depleted in AMF species. However, the level of $\mathrm{CO}$ present in the starting blends had no discernable influence on the extent of this enrichment. Although relatively more AMF solids were solubilized in the most dilute samples (Figure 2), the compositional data does not point to the selective solubilization of particular AMF species. It was speculated that the selective solubilization of short-chain or unsaturated AMF FA might lead to better packing of the AMF TAG and the subsequent formation of the $\beta$-crystal. There was no evidence of this in the fractions obtained after $24 \mathrm{~h}$ of crystallization, although there may be differences in solubilization between the blends during the slow crystallization process. The FA composition of the crystalline fractions is shown in Table 7.

It is clear by comparing Tables 4 and 7 that the crystalline fractions contained relatively more AMF species (12:0 and 14:0) than the starting blends. For example, for each blend, the ratio of 12:0 in the crystalline fraction to 12:0 in the starting blend is greater than unity. This ratio increased slightly with $\mathrm{CO}$ concentration. Relatively more AMF FA were present in the fractions at higher levels of $\mathrm{CO}$ dilution. For example, based on 14:0, the 1:2 fraction was enriched by a factor of only 1.1 (4.0/3.5), whereas the 1:8 fraction was enriched by a factor of $2.3(2.8 / 1.2)$. This enrichment corresponds to the improved separation that was achieved for the more dilute AMF:CO blends. Still, the fractions' oleic acid composition reveals extensive contamination with $\mathrm{CO}$. Anhydrous milk fat and CO contained roughly 26 and $72 \% 18: 1$, respectively. In the starting blends, the proportion of 18:1 ranged from 56.7 to $67.0 \%$ for the 1:2 and 1:8 blends, respectively (Table 4 ). Table 7 shows that the crystalline fractions contained between 56.4 and 58.5\% 18:1. Although each fraction contains a lot more 18:1 relative to AMF, there is relatively less in the fractions from the more dilute blends. With the 1:2 ratio, for example, the 18:1 content of the fraction is the same as in the starting blend $(P>0.05)$. With the 1:8 ratio, the crystalline fraction contained only $58.5 \%$ 18:1 compared with $67.0 \%$ in the starting blend. Again, larger differences in composition were observed for the ratios in which better separation was obtained. Although co-crystallization occurs between the fractions in milk fat, it is unlikely that significant amounts of $\mathrm{CO}$ would be co-crystallized within the network. Although this cannot be entirely ruled out, physical entrapment of $\mathrm{CO}$ within the fractions is the most likely explanation for the observed contamination.

Melting profiles of the AMF:CO blends and the crystalline fractions were determined. These results are shown in Figure 5.

The SFC values for the blends and the crystalline fractions (Figure 5A and B) were much lower than those for AMF (Figure 5C). The most dilute blends (1:5 to 1:8) had especially shallow melting profiles. Figure 5 shows that the crystalline fractions did have higher SFC than the starting blends. For example, although each blend contained fewer than $15 \%$ solids at $0^{\circ} \mathrm{C}$, all the crystalline fractions had SFC between 15 and $20 \%$ at the same temperature. The level of $\mathrm{CO}$ dilution influenced the fractions' SFC. Figure $5 \mathrm{~B}$ shows that, especially between 15 and $40^{\circ} \mathrm{C}$, higher SFC were observed for the 1:7 and 1:8 over the other blends. Although 

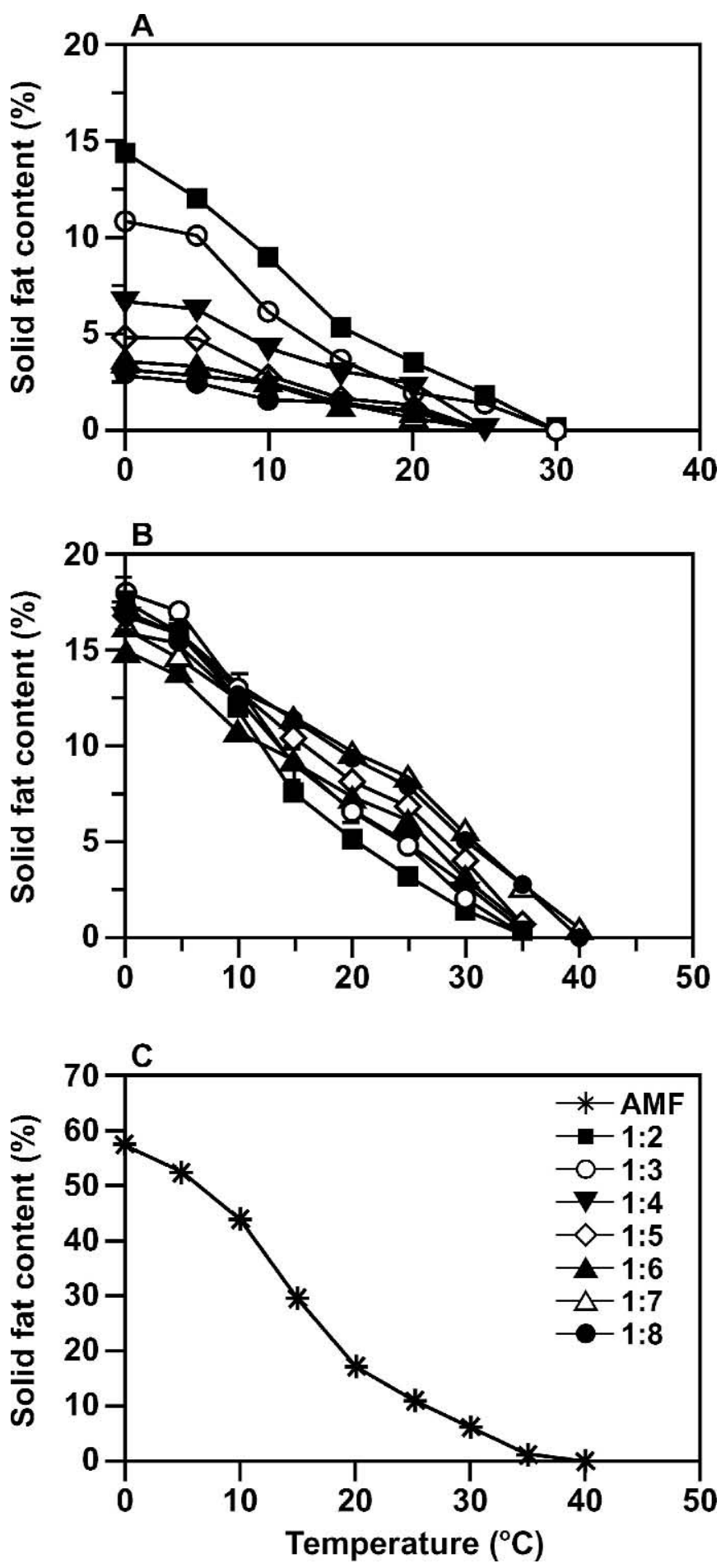

Figure 5. Equilibrium solid fat content $(\%)$ vs. temperature $\left({ }^{\circ} \mathrm{C}\right)$ for the anhydrous milk fat:canola oil blends (A), the partially crystalline fractions (B), and anhydrous milk fat (C).

these blends melted by $25^{\circ} \mathrm{C}$ (Figure 5A), their fractions melted by $40^{\circ} \mathrm{C}$ (Figure 5B). Compared with AMF, the fractions were much more liquid at nearly every tem- perature because of the entrapment of canola oil (18:1). However, the 1:7 and 1:8 fractions (for which the best solid-liquid separation was observed) did have slightly higher SFC than $\mathrm{AMF}$ at $35^{\circ} \mathrm{C}(3 \%$ vs. $1 \%)$, indicating some fractionation of the higher-melting milk fat TAG. However, the "fractions" obtained in this study are not equivalent to those from other studies where a true separation of the liquid and crystalline phases is achieved. Milk fat fractionated at $5^{\circ} \mathrm{C}$ using ethyl acetate contained less than 10\% 18:1 and had an SFC greater than $96 \%$ below $30^{\circ} \mathrm{C}$ (Marangoni and Lencki, 1998; Wright et al., 2000b). Similarly, the stearins obtained by the Tirtiaux process (Deffense, 1987) have much higher solids than observed in this study.

\section{CONCLUSIONS}

Milk fat was crystallized in the presence of CO. Different crystallization behaviors, microstructures, and polymorphic forms were observed for high and low levels of dilution. Interestingly, the $\beta$-polymorph was observed when the 1:8 blend was crystallized slowly but not in the case of the 1:2 sample. Some solubilization of AMF solids into $\mathrm{CO}$ was observed, the amount being proportionally higher with increasing CO dilution. Compositional analysis showed enrichment of AMF species in the crystalline fractions over the starting blends. However, significant levels of oil entrapment were observed, even for the 1:7 and 1:8 blends. Although differences were observed between the SFC profiles for the blends and crystalline fractions, a substantially altered product was not obtained. The limitation would seem to be the separation of liquid and solids. With either better centrifuging or pressing, AMF blending and fractionation with $\mathrm{CO}$ may be useful for the manufacture of crystalline fractions with unique functionalities. Also, although mixing of AMF and $\mathrm{CO}$ in the liquid state may be a practical concern, transfer of AMF TAG, carotenoids, and flavor compounds into the liquid phase could result in a unique oil composition.

\section{ACKNOWLEDGMENTS}

The authors acknowledge the financial support of the Natural Sciences and Engineering Research Council of Canada and the Ontario Ministry of Food and Agriculture. The technical assistance of Gianfranco Mazzanti is also gratefully acknowledged.

\section{REFERENCES}

American Oil Chemists' Society. 1993. Official method Cd16-81 in Official Methods and Recommended Practices of the American Oil Chemists' Society. 4th ed. AOCS Press, Champaign, IL. 
Arul, J., A. Boudreau, J. Makhlouf, R. Tardif, and T. Bellavia. 1988. Fractionation of anhydrous milk fat by short-path distillation. J. Am. Oil Chem. Soc. 65:1642-1646.

Bhaskar, A. R., S. S. H. Rizvi, and C. Bertoli. 1998. A comparison of physical and chemical properties of milk fat fractions obtained by two processing techniques. J. Am. Oil Chem. Soc. 75:1249-1264.

Black, R. G. 1975. Partial crystallization of milkfat and separation of fractions by vacuum filtration. Aust. J. Dairy Technol. 30:153-156.

Breeding, C. J., and R. T. Marshall. 1995. Crystallization of butter oil and separation by filter-centrifugation. J. Am. Oil Chem. Soc. 72:449-453.

Campos, R., J. W. Litwinenko, and A. G. Marangoni. 2003. Fractionation of milk fat by short-path distillation. J. Dairy Sci. 86:735-745

Deffense, E. 1987. Multi-step butteroil fractionation and spreadable butter. Fat Sci. Technol. 89:502-507.

deMan, J. M. 1961. Physical properties of milk fat. II. Some factors influencing crystallization. Dairy Res. 28:117-123.

Illingworth, D. 2002. Fractionation of fats. Pages 411-448 in Physical Properties of Lipids. A. G. Marangoni, and S. S. Narine, ed. Marcel Dekker, New York, NY.

Jensen, R. G., and D. S. Newburg. 1995. Milk lipids. Pages 545-575 in Handbook of milk composition. R. G. Jensen, ed. Academic Press, New York, NY.

Kaylegian, K. E. 1999. The production of specialty milk fat ingredients. J. Dairy Sci. 82:1433-1439.

Kaylegian, K. E., and R. C. Lindsay. 1992. Performance of selected milk fat fractions in cold-spreadable butter. J. Dairy Sci. 75:3307-3317.

Kaylegian, K. E., and R. C. Lindsay. 1994. Handbook of Milkfat Fractionation Technology and Applications. AOCS Press, Champaign, IL.

Makhlouf, J., J. Arul, A. Boudreau, P. Verret, and M. R. Sahasrabudhe. 1987. Fractionnement de la matiere grasse laitiere par cristallisation simple et son utilisation dans la fabrication de beurres mous. Can. Inst. Food Technol. J. 20:236-244.

Marangoni, A. G., and R. W. Lencki. 1998. Ternary phase behaviour of milk fat fractions. J. Agric. Food Chem. 46:3879-3884.

McGillivray, W. A. 1972. Softer butter from fractionated fat or by modified processing. N.Z. J. Dairy Sci. Technol. 7:111-112.
Rizvi, S. S. H., and A. R. Bhaskar. 1995. Supercritical fluid processing of milk fat: Fractionation, scale-up, and economics. Food Technol Feb.:90-100.

Rosenberg, M. 2000. Applications for fractionated milk fat in modulating rheological properties of milk and whey composite gels. Aust. J. Dairy Technol. 55:56-60.

Rousseau, D., A. G. Marangoni, and K. R. Jeffrey. 1998. The influence of chemical interesterification on the physicochemical properties of complex fat systems II. Morphology and polymorphism. J. Am. Oil Chem. Soc. 75:1833-1839.

Schaap, J. W., H. T. Badings, D. G. Schmidt, and E. Frede. 1975. Differences in butterfat crystals crystallized from acetone and from the melt. Neth. Milk Dairy J. 29:242-252.

Shukla, A., A. R. Bhaskar, S. S. H. Rizvi, and S. J. Mulvaney. 1994. Physicochemical and rheological properties of butter made from supercritically fractionated milk fat. J. Dairy Sci. 77:45-54.

ten Grotenhuis, A., G. A. van Aken, K. F. van Malssen, and H. Schenk. 1999. Polymorphism of milk fat studied by differential scanning calorimetry and real-time x-ray powder diffraction. J. Am. Oil Chem. Soc. 76:1031-1039.

Timms, R. E. 1978. The solubility of milk fat, fully hardened milk fat and milk fat hard fraction in liquid oils. Aust. J. Dairy Technol. 33:130-135

Timms, R. E. 1979. The physical properties of blends of milk fat with beef tallow and beef tallow fractions. Aust. J. Dairy Technol. 34:60-65.

Timms, R. E. 1980. The phase behaviour and polymorphism of milk fat, milk fat fractions and fully hardened milk fat. Aust. J. Dairy Technol. 35:47-53.

VanAken, G. A., E. tenGrotenhuis, A. J. vanLangeveld, and H. Schenk. 1999. Composition and crystallization of milk fat fractions. J. Am. Oil Chem. Soc. 76:1323-1331.

Vanhoutte, B., K. Dewettinch, and B. Vanlergerghe. 2003. Monitoring milk fat fractionation: filtration properties and crystallization kinetics. J. Am. Oil Chem. Soc. 80:213-218.

Woodrow, I. L., and J. M. deMan. 1968. Polymorphism in milk as shown by x-ray diffraction and infrared spectroscopy. J. Dairy Sci. 51:996-1000

Wright, A. J., R. W. Hartel, S. S. Narine, and A. G. Marangoni. 2000a. The effect of minor components on milk fat crystallization. J. Am. Oil Chem. Soc. 77:463-475.

Wright, A. J., S. E. McGauley, S. S. Narine, W. M. Willis, R. W. Lencki, and A. G. Marangoni. 2000b. Solvent effects on the crystallization behavior of milk fat fractions. J. Agric. Food Chem. 48:1033-1040. 